\title{
Plasma prostacyclin from birth to adolescence
}

\author{
P KÄÄPÄ, L VIINIKKA, AND O YLIKORKALA \\ Department of Paediatrics, Department of Clinical Chemistry, and Department of Obstetrics and Gynaecology, \\ University of Oulu, Finland
}

SUMMARY The plasma concentration of 6-keto-prostaglandin $F_{1 \alpha}$ (6-keto-PGF $F_{1 \alpha}$ ), the stable hydration product of prostacyclin, was measured by radioimmunoassay in 111 healthy children aged between 1 day and 16 years and in 21 healthy adults aged between 21 and 72 years. The 6-keto$\mathrm{PGF}_{1 \alpha}$ levels in children up to age 16 years were higher than those in adults. During the first 4 days of life the plasma concentrations of $6-$ keto- $^{-} \mathrm{PGF}_{1 \alpha}$ in term infants were higher $(\mathrm{P}<0.05)$ than the respective levels in preterm infants. There was no difference between the 6-keto-PGF levels $_{1 \alpha}$ measured simultaneously in umbilical arterial and peripheral venous plasma in 7 newborn infants. Maternal pre-eclampsia or epidural analgesia during labour, mode of delivery, birthweight, or sex of the infants were not related to the plasma 6-keto-PGF ${ }_{1 \alpha}$ levels on the first day of life. High levels of vasodilatory and anti-aggregatory prostacyclin during the first days of life may play a role in the postnatal adaptation of the circulation and platelet function.

Prostacyclin $\left(\mathrm{PGI}_{2}\right)$ is a recently discovered hormone which is generated from prostaglandin endoperoxides, mainly by way of the vascular walls. It is characterised by anti-aggregatory and vasodilatory properties. $\mathbf{P G I}_{2}$ is unstable; most of it is rapidly converted non-enzymatically in physiological $\mathrm{pH}$ to 6-keto-prostaglandin $\mathrm{F}_{1 \alpha}$ (6-ketoPGF $_{1 \alpha}$ ), the concentration of which, in a biological sample, reflects the production of $\mathrm{PGI}_{2}{ }^{1}$

$\mathrm{PGI}_{2}$ is the major product of prostaglandin biosynthesis in vascular tissues of fetal animals. ${ }^{23}$ The human umbilical cord and placental vessels also generate much $\mathrm{PGI}_{2}$ in vitro. ${ }^{3-5}$ The vasodilatory $\mathrm{PGI}_{2}$ may contribute to the low peripheral resistance typical of the fetal circulation. ${ }^{467}$ There is evidence to suggest that $\mathrm{PGI}_{2}$ is important in adults, ${ }^{1}$ but little is known about the endogenous $\mathrm{PGI}_{2}$ in newborn infants or older children. Therefore we studied plasma $\mathbf{P G I}_{2}$ in children from birth to adolescence.

\section{Material and methods}

Subjects. One hundred and eleven healthy children were studied with the approval of the local committee of ethics. Twenty-one preterm infants (born at 29-36 weeks' gestation) were studied, most of them on two occasions at age 1-4 or 6-8 days, or 2-4 weeks of life. Thirty-eight term infants (born at 37-42 weeks' gestation) were similarly studied during the first 4 weeks of life. Fifteen $(7$ term and 8 preterm) infants were delivered by caesarean section and 44 infants vaginally. None had clinical evidence of heart or lung diseases. Five mothers had had pre-eclampsia (blood pressure over 150/100 $\mathrm{mmHg}$ ), and segmental lumbar analgesia using low-dose bupivacaine infusions epidurally was used for 6 mothers during labour. In addition, 52 healthy children were studied between ages 3 months and 16 years and 21 healthy adults $(5$ men, 16 women) between ages 21 and 72 years. No subject had used drugs known to interfere with prostaglandin synthesis within the 10 days before the start of the study.

Sampling and analytical procedures. Blood samples (1-2 ml) were collected either by venepuncture from a peripheral vein or from aortic blood via an umbilical arterial catheter, with the exception of 7 infants, from whom samples from both sites were collected simultaneously. In addition, blood specimens were collected separately from the umbilical cord vein and artery immediately after placental expulsion in 7 term vaginal deliveries. Most $(95 \%)$ blood samples were obtained at the time of routine clinical monitoring.

The blood was drawn into ice-cold heparinised tubes containing acetylsalicylic acid at the final concentration of $20 \mu \mathrm{mol} / 1$. Plasma was separated immediately by centrifugation at $+4^{\circ} \mathrm{C}$ and stored frozen $\left(-20^{\circ} \mathrm{C}\right)$ until assayed for 6-keto-PGF $1 \alpha$ with radioimmunoassay. Plasma was acidified to pH 3 with hydrochloride acid and extracted 4 times 
with ethyl acetate, The combined organic phases were evaporated to dryness under a nitrogen stream and two different parts, both in duplicate, of the residue dissolved in ethanol, were taken for the saturation analysis using specific antibodies raised in rabbits against 6-keto-PGF ${ }_{1 \alpha}$-bovine serum albumin conjugate and a tritiated tracer (New England Nuclear Corporation, Boston, Mass, USA). The specificity of the antibody was tested against 22 other prostaglandins or related compounds, and all crossreactions were less than $0.1 \%$ at the $50 \%$ displacement level, except for 6-keto-PGE had a crossreaction of $1.8 \%$. The recovery of added 6-keto-PGF - $_{1 \alpha}(50-200 \mathrm{pg} / \mathrm{ml})$ into plasma was between 84 and $104 \%(n=15)$, and the coefficients of intra-assay and interassay variations were between $6 \cdot 8-8 \cdot 5$ and $9 \cdot 3-14 \cdot 2 \%$, respectively. The plasma 6-keto-PGF Pa $_{1 \alpha}$ measurement as an index of $\mathbf{P G I}_{2}$ production was further validated by demonstrating a linear relationship $(\mathrm{r}=0.958, \mathrm{P}<0.001, \mathrm{n}=24)$ between infused $\mathrm{PGI}_{2}$ doses (1-8 $\mathrm{ng} / \mathrm{kg}$ per min) and the rises in 6-keto-PGF ${ }_{1 \alpha}$ levels in the plasma of 6 healthy adults. We could also show in vitro works that the release of radioimmunoassayable 6-keto-PGF ${ }_{1 \alpha}$ by the umbilical cord vessels is inhibited with indomethacin in a concentration dependent manner, which gives further validation for 6-keto-PGF ${ }_{1 \alpha}$ measurement.

Statistical analysis. The results were tested using the Mann Whitney rank sum test.

\section{Results}

Cord blood. The concentrations of 6-keto-PGF $1 \alpha$ in umbilical arterial plasma $(1002 \pm 150 \mathrm{pg} / \mathrm{ml}$; mean $\pm \mathrm{SE}$ ) were higher than those in umbilical venous plasma $(538 \pm 116 \mathrm{pg} / \mathrm{ml} ; \mathbf{P}<0.05)$ or in term infants on the first day of life $(397 \pm 25 \mathrm{pg} / \mathrm{ml}$; $\mathbf{P}<0.001$ ). However, the 6-keto-PGF ${ }_{1 \alpha}$ levels in umbilical venous blood did not differ from those in term infants on the first day of life $(P>0.05)$.

\section{Term infants.}

\section{The first day of life}

There was no difference $(P>0.05)$ between the 6keto-PGF ${ }_{1 \alpha}$ levels in samples taken simultaneously from the umbilical artery $(396 \pm 80 \mathrm{pg} / \mathrm{ml})$ and the peripheral vein $(410 \pm 65 \mathrm{pg} / \mathrm{ml})$. Consequently, the neonatal concentrations of 6-keto-PGF $1 \alpha$ measured in umbilical arterial or peripheral venous plasma were combined. The 6-keto-PGF $1 \alpha$ levels on the first day of life were higher than those in older children and adults (Table). Maternal pre-eclampsia
Table Plasma concentrations of 6-keto-PGF $1 \alpha$ (mean $\pm S E$ ) at different ages

\begin{tabular}{|c|c|c|c|c|}
\hline \multirow[t]{2}{*}{ Age } & \multicolumn{2}{|c|}{ Term infants } & \multicolumn{2}{|c|}{ Preterm infants } \\
\hline & No & $\begin{array}{l}\text { 6-keto-PGF } \alpha \\
(\mathrm{pg} / \mathrm{ml})\end{array}$ & No & $\begin{array}{l}\text { 6-keto-PGF } F_{1} \alpha \\
(\mathrm{pg} / \mathrm{ml})\end{array}$ \\
\hline $\begin{array}{l}\text { Day 1 } \\
\text { Days 2-4 } \\
\text { Days 6-8 } \\
\text { Weeks 2-4 } \\
\text { Months 3-6 }\end{array}$ & $\begin{array}{r}18 \\
17 \\
6 \\
6 \\
10\end{array}$ & $\begin{array}{l}397 \pm 25^{* *} \\
367 \pm 36^{* *} \\
191 \pm 20^{* *}+\dagger \\
196 \pm 29^{* *}+\dagger \\
231 \pm 25^{* *}+\dagger\end{array}$ & $\begin{array}{l}9 \\
8 \\
6 \\
5\end{array}$ & $\begin{array}{l}283 \pm 40^{* *} \S \S \\
285 \pm 66^{* *} \S \S \\
192 \pm 16^{* *} \\
180 \pm 17^{* *} \dagger\end{array}$ \\
\hline $\begin{array}{l}\text { Years } 1-4 \\
\text { Years 5-10 } \\
\text { Years 11-16 } \\
\text { Adults 21-72 }\end{array}$ & $\begin{array}{r}23 \\
7 \\
11 \\
21\end{array}$ & $\begin{array}{l}185 \pm 12^{* *}+\dagger \\
145 \pm 16^{*}+\dagger \\
138 \pm 14^{*} \dagger \dagger \\
85 \pm 7 \dagger \dagger\end{array}$ & & \\
\hline
\end{tabular}

* $\mathbf{P}<0.01,{ }^{* *} \mathbf{P}<0.001$ in comparison with the adult levels. $\dagger \mathbf{P}<0.05$, $\dagger+\mathbf{P}<0.001$ in comparison with the first-day levels. $\S \S \mathbf{P}<0.05$ in comparison with the term infants.

or epidural analgesia, the mode of delivery (caesarean section or vaginal delivery), the birthweight, or gender of the infants had no relation to the concentrations of 6-keto-PGF $1 \alpha$ in neonatal plasma on the first day of life.

\section{From the second day to 16 years of life}

The concentrations of 6-keto-PGF $1 \alpha$ stayed in the range of the first-day levels for the next 1-3 days, but rapidly fell at age 6-8 days (Table). With advancing age of the children the 6-keto-PGF ${ }_{1 \alpha}$ concentrations declined towards the adult levels, but still in adolescence, the 6-keto-PGF Ia $_{10}$ levels were higher than those in adults (Table).

Preterm infants. The concentrations of 6-keto-PGF ${ }_{1 \alpha}$ in preterm infants were lower $(P<0.05)$ than those in term infants on the first 4 days of life, whereas no differences in these levels were found later (Table). The age-dependent decrease in 6-ketoPGF $_{1 \alpha}$ levels took place later in preterm than term infants (Table).

\section{Discussion}

It is clear from our data that plasma $\mathrm{PGI}_{2}$, as measured by its metabolite in peripheral blood, is greatly increased during the first days of life. This may reflect the high $\mathrm{PGI}_{2}$ production typical for the fetal vasculature ${ }^{2-5}$, as also seen from the high concentrations of 6-keto-PGF ${ }_{1 \alpha}$ in the umbilical cord vessels in our study. Judged from the higher levels of 6-keto-PGF $\alpha$ in the umbilical artery compared with umbilical vein, it seems likely that the fetal 6-keto-PGF ${ }_{1 \alpha}$ contributes to the increased 6-keto-PGF ${ }_{1 \alpha}$ concentrations in maternal plasma during pregnancy ${ }^{8}$ or labour. ${ }^{9}$ Perhaps the 
fetus through this $\mathrm{PGI}_{2}$ surge helps to control the blood flow in its own placenta.

Since $\mathrm{PGI}_{2}$ is produced particularly by the pulmonary vascular bed, ${ }^{10}$ the high 6 -keto-PGF ${ }_{1 \alpha}$ levels on the first days of life might also be a consequence of the increased output of $\mathrm{PGI}_{2}$ by the newly ventilated lungs. This was suggested in a study that showed there was increased release of vasodilatory $\mathrm{PGI}_{2}$ from the fetal lung after the start of respiration.11 Our results further suggest that the fetal $\mathrm{PGI}_{2}$ synthesis is not fully matured before term, since the concentrations of 6-keto-PGF ${ }_{2} \alpha$ in preterm infants on the first days of life were significantly lower than those in term infants.

The biological significance of the high $\mathbf{P G I}_{2}$ concentrations during the first days of life is not known. $\mathrm{PGI}_{2}$ could be the endogenous pulmonary vasodilator known to be present in newborn infants. ${ }^{12}$ This is supported by the pulmonary vasodilatation after PGI $_{2}$ infusions in near-term goats ${ }^{13}$ and lambs. ${ }^{14}$ In humans, the pulmonary vascular resistance decreases rapidly during the first few days of life..$^{15}$ This decrease matches well with the high PGI $_{2}$ levels on the first 4 days we observed in our study. Thus our data could support the hypothesis of $\mathrm{PGI}_{2}$ as a pulmonary vasodilator. Increased production of anti-aggregatory $\mathrm{PGI}_{2}$ could also provide an explanation for the impaired platelet aggregation in newborn infants. ${ }^{16}$ After the rapid decrease during the first week of life, the $\mathrm{PGI}_{2}$ levels declined slowly towards the adult values. Similar age-dependent decrease of $\mathrm{PGI}_{2}$ production has been found in rat aortas. ${ }^{17}$ Perhaps this age-related PGI $_{2}$ decline might provide one explanation for the changes in the haemodynamics observed in childhood-for example, the rise in systemic vascular resistance. ${ }^{18}$

We conclude that the healthy term infant circulates more $\mathbf{P G I}_{2}$ than the healthy preterm infant, the older child, or adult. The involvement of $\mathrm{PGI}_{2}$ in neonatal disorders, such as persistent fetal circulation or respiratory distress syndrome, should be studied.

This study was supported by the Medical Research Council, The Academy of Finland, and the Alma and $\mathrm{K}$ A Snellman Foundation.

\section{References}

1 Moncada S, Vane J R. Unstable metabolites of arachi- donic acid and their role in haemostasis and thrombosis. Br Med Bull 1978; 34: 129-35.

2 Pace-Asciak C R, Rangaraj G. The 6-ketoprostaglandin $F_{1 \alpha}$ pathway in the lamb ductus arteriosus. Biochim Biophys Acta 1977; 486: 583-5.

3 Terragno N A, Terragno A, McGiff J C. Role of prostaglandins in blood vessels. Semin Perinatol 1980; 4: 85-90.

4 Remuzzi G, Misiani R, Muratore D, et al. Prostacyclin and human foetal circulation. Prostaglandins 1979; 18: 341-8.

5 Hamberg M, Tuvemo T, Svensson J, Johnsson C-E. Formation and action of prostacyclin in the isolated human umbilical artery. Acta Physiol Scand 1979; 106: 289-92.

6 Tuvemo T. Role of prostaglandins, prostacyclin, and thromboxanes in the control of the umbilical-placental circulation. Semin Perinatol 1980; 4: 91-5.

7 Pomerantz K, Sintetos A, Ramwell P. The effect of prostacyclin on the human umbilical artery. Prostaglandins 1978; 15: 1035-44.

8 Lewis P J, Boylan P, Friedman L A, Hensby C N, Downing I. Prostacyclin in pregnancy. Br Med J 1980; 280: 1581-2.

9 Ylikorkala O, Mäkäräinen L, Viinikka L. Prostacyclin production increases during human parturition. $B r J$ Obstet Gynaecol 1981; 88: 513-6.

10 Gryglewski R J, Korbut R, Ocetkiewicz A. Generation of prostacyclin by lungs in vivo and its release into the arterial circulation. Nature 1978; 273: 765-7.

11 Leffler C W, Hessler J R, Terragno N A. Ventilation induced vasodilator prostaglandin release from fetal lungs. Fed Proc 1979; 38: 1236.

12 Cassin S. Role of prostaglandins and thromboxanes in the control of the pulmonary circulation in the fetus and newborn. Semin Perinatol 1980; 4: 101-7.

13 Cassin S, Winikor I, Tod M L. Prostacyclin and fetal vascular resistance. Physiologist 1978; 21 : 17.

14 Leffler C W, Hessler J R. Pulmonary and systemic vascular effects of exogenous prostaglandin $I_{2}$ in fetal lambs. Eur J Pharmacol 1979; 53: 37-42.

15 Roberton N R C. Perinatal physiology. In: Godfrey S, Baum J D, eds. Clinical paediatric physiology. London: Blackwell, 1979: 134-92.

16 Mull M M, Hathaway W E. Altered platelet function in newborns. Pediatr Res 1970; 4: 229-37.

17 Chang W-C, Murota S-I, Nakao J, Orimo H. Agerelated decrease in prostacyclin biosynthetic activity in rat aortic smooth muscle cells. Biochim Biophys Acta 1980; 620: 159-66.

18 Rudolph A M. Cardiac catheterization and angiocardiography. In: Rudolph A M, ed. Congenital diseases of the heart. Chicago: Year Book Medical Publishers, 1974: 49-167.

Correspondence to Dr Pekka Kääpä, Department of Paediatrics, University of Oulu, SF-90220 Oulu 22, Finland.

Received 5 October 1981 